

\title{
PRIMARY LINGUAL TUBERCULOSIS, A RARE CASE REPORT
}

\author{
PIERWOTNA GRUŹLICA JĘZYKA, RZADKI OPIS PRZYPADKU
}

\author{
Nithya Raghunath ${ }^{1}$, Sreekar Harinatha ${ }^{2}$, Sreeharsha Harinatha ${ }^{3}$ \\ ${ }^{1}$ Department of Dermatology, MVJ Medical College and Research Hospital, \\ Bangalore, India \\ ${ }^{2}$ Department of Plastic and Reconstructive Surgery, Christian Medical College, \\ Vellore, India \\ ${ }^{3}$ Department of Urology, SMS Medical College, Jaipur, India
}

Corresponding author: Dr. Sreekar Harinatha

drsreekarh@yahoo.com

Sir,

Lingual tubercular lesions are rare occurrences even in endemic countries like India. The lesions can present in a variety of appearances. They may masquerade as vascular malformations or malignant neoplasm clinically. Cases of lingual tuberculosis have been described from 1888 [1]. There have been occasional reports of lingual tuberculosis since then $[2,3]$. The clinical diagnosis is often difficult if not impossible as it is rare to suspect especially if it presents as a diffuse swelling. Most often, the diagnosis is made either by fine needle aspiration cytology or histopathological examination of a biopsy from the lesion.

In this case, we present a patient who initially complained of a lingual swelling since 3 years. It had been gradually increasing in size and had occasionally ulcerated with minimal bloody discharge. The swelling was over the dorsal aspect of tongue and measured around $2.5 \times 2.5 \mathrm{cms}$ in size (Fig. 1). It was firm in consistency with some areas being harder. There were no palpable cervical lymph nodes. Clinically a diagnosis of lymphatic malformation was made and excision biopsy was done (Fig. 2). Histopathological examination revealed numerous caseating epithelioid and giant cells granulomata, containing scanty acid fast bacilli. A final histopathological diagnosis of tuberculous lesion was later made and was supported by a positive PPD test and Mycobacterial culture from a sputum specimen. The patient was started on antituberculous therapy and follow up showed good initial response.
Many believe that the rarity of oral tuberculosis is due to the continuous cleansing of the oral mucosa by saliva, the presence of a variable normal flora in addition to the presence of submucosal antibodies which gives the buccal mucosa a normal resistance [4]. The case differs from previously reported cases because the patient presented with a nodular and tumor-like mass which was clinically mistaken for a lymphatic malformation.

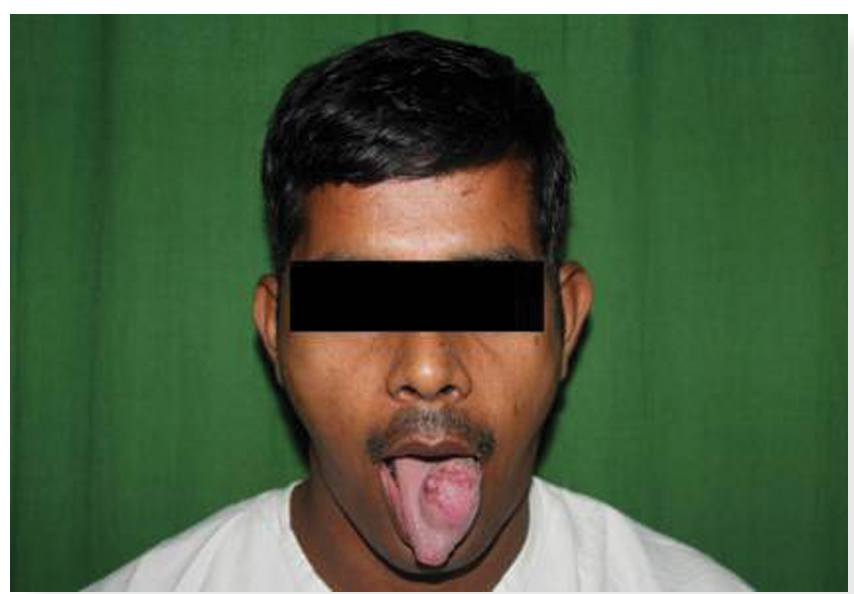

Figure 1. Pre-operative photograph showing the lingual swelling 


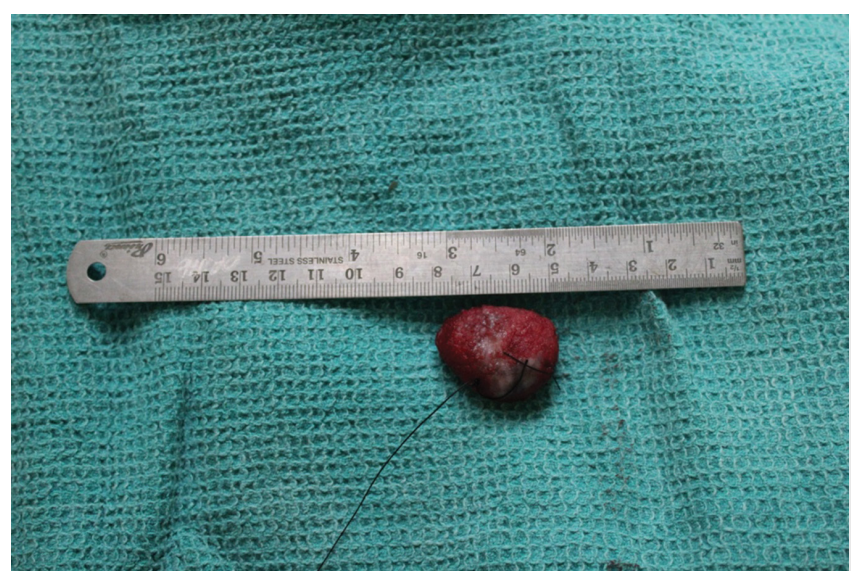

\section{REFERENCES}

1. Shepherd FJ: Excision of the Tongue Followed by Death from Acute Miliary Tuberculosis. Ann Surg. 1888; 8: 368-371.

2. Gupta A, Shinde KJ, Bhardwaj I: Primary lingual tuberculosis: a case report. J Laryngol Otol. 1998; 112: 86-87.

3. Sareen D, Sethi A, Agarwal AK: Primary tuberculosis of the tongue: a rare nodular presentation. Br Dent J. 2006; 200: 321322.

4. Sezer B, Zeytinoglu M, Tuncay U, Unal T: Oral mucosal ulceration: a manifestation of previously undiagnosed pulmonary tuberculosis. J Am Dent Assoc. 2004; 135: 336-340.

Figure 2. Excised specimen

Copyright by Nithya Raghunath, et al. This is an open access article distributed under the terms of the Creative Commons Attribution License, which permits unrestricted use, distribution, and reproduction in any medium, provided the original author and source are credited. 